\title{
Plankton Community Succession in Artificial Systems Subjected to Cyanobacterial Blooms Removal using Chitosan-Modified Soils
}

\author{
Qingyun Yan • Yuhe Yu • Weisong Feng • Gang Pan • \\ Hao Chen • Juan Chen • Bo Yang - Xuemei Li • \\ Xiang Zhang
}

Received: 4 June 2008 /Accepted: 31 July 2008 /Published online: 6 September 2008

(C) Springer Science + Business Media, LLC 2008

\begin{abstract}
Using artificial systems to simulate natural lake environments with cyanobacterial blooms, we investigated plankton community succession by polymerase chain reaction-denaturing gradient gel electrophoresis (PCRDGGE) fingerprinting and morphological method. With this approach, we explored potential ecological effects of a newly developed cyanobacterial blooms removal method using chitosan-modified soils. Results of PCR-DGGE and morphological identification showed that plankton communities in the four test systems were nearly identical at the beginning of the experiment. After applying the newly developed and standard removal methods, there was a shift in community composition, but neither chemical conditions nor plankton succession were significantly affected by the cyanobacteria removal process. The planted Vallisneria natans successfully recovered after cyanobacteria removal, whereas that in the box without removal process did not. Additionally, canonical correspondence analysis indicated
\end{abstract}

Q. Yan $\cdot$ Y. Yu $\cdot$ W. Feng $\cdot$ X. Li $\cdot$ X. Zhang

State Key Laboratory of Freshwater Ecology and Biotechnology, Institute of Hydrobiology, Chinese Academy of Sciences,

Wuhan 430072, People's Republic of China

G. Pan $\cdot$ H. Chen $\cdot$ J. Chen $\cdot$ B. Yang

State Key Laboratory of Environmental Aquatic Chemistry,

Research Center for Eco-environmental Sciences,

Chinese Academy of Sciences,

Beijing 100085, People's Republic of China

Q. Yan $\cdot$ J. Chen $\cdot$ B. Yang $\cdot$ X. Li $\cdot$ X. Zhang

Graduate School of Chinese Academy of Sciences,

Beijing 100039, People's Republic of China

Y. Yu ( $\square)$

7\# Donghu South Road,

Wuhan 430072, People's Republic of China

e-mail: yhyu@ihb.ac.cn that other than for zooplankton abundance, total phosphorus was the most important environmental predictor of planktonic composition. The present study and others suggest that dealing with cyanobacteria removal using chitosan-modified soils can play an important role in controlling cyanobacterial blooms in eutrophicated freshwater systems.

\section{Introduction}

Water eutrophication, considerably accelerated by the human activity in recent decades, is one of the most challenging environmental problems in the world [22]. In the presence of dramatically increased nutrient loading, the pristine state of most shallow lakes, generally rich in submerged vegetation [16], has been substantially reduced, leaving high loadings of algal biomass. Unfortunately, reduction of nutrient concentrations is often insufficient to reverse the process and recover submerged macrophytes because recovery requires substantially lower nutrient levels than those at which the collapse of the vegetation occurred $[9,16]$.

Cyanobacterial bloom is an extreme response to eutrophication, and many efforts have been made to control this bloom. However, control results have often been unsatisfactory. Recently, one simple technology for quickly removing harmful cyanobacterial blooms from freshwater using chitosan-modified local soils has been developed by Pan and colleagues [10, 11, 26]. They suggested that it may provide a long-term strategy for permanently remediating algae-clogged lakes. However, its ecological effects require evaluation before it is widely applied. Local mussels [Cristaria plicata (Leach)] and 
submerged macrophytes (Myriophyllum spicatum) were found to be unaffected by this process [26], but its effects on other more sensitive organisms, such as plankton, have not been evaluated. These planktonic organisms are very sensitive to physicochemical perturbations, and environmental changes are generally marked by rapid shifts in their density and diversity [1, 2, 19]. Furthermore, planktonic organisms play an important ecological role when a lake switches between macrophyte-dominant and phytoplankton-dominant states. Therefore, it is especially important to investigate the plankton community succession when an ecosystem is subjected to cyanobacterial blooms removal.

The purpose of this paper was to explore potential ecological effects of the newly developed cyanobacterial blooms removal method by investigating plankton community succession through a laboratory simulation experiment. The experiment also produces basic data for elucidating the switching mechanism between macrophyte-dominant and phytoplankton-dominant states.

\section{Materials and Methods}

\section{Experimental Design}

Four artificial systems, each $1 \times 1 \times 1 \mathrm{~m}$ in size, with about $10 \mathrm{~cm}$ of sediments were set up to simulate natural lake environments with cyanobacterial blooms. Water used in the ecological simulation experiment was collected from Taihu Lake during cyanobacterial blooms (in July 2007). When the natural lake water was transferred into the experimental boxes, aeration treatment and light/dark cycle $(12 / 12 \mathrm{~h})$ was applied to simulate natural environments; this treatment persisted for about $48 \mathrm{~h}$. The water cycled among the four boxes for $12 \mathrm{~h}$ to produce identical conditions at the beginning of the experiment. Before applying cyanobacterial bloom treatments, cycling was stopped and water levels in the four boxes were kept constant. Different treatments were then applied to the four boxes (no. 1, as a control; no. 2, removal of cyanobacterial cells using chitosan-modified soils; no. 3, planting seeds and seedling of Vallisneria natans; no. 4, removal of cyanobacterial cells and planting seeds and seedling of $V$. natans). Additionally, three mature $V$. natans (about $15 \mathrm{~cm}$ high) were planted in boxes 3 and 4 .

The cyanobacterial blooms in boxes 2 and 4 were removed on Jul. 31, 2007 according to the method described by Pan et al. [10, 11]. In brief, $7.5 \mathrm{mg} \mathrm{l}^{-1}$ (final concentration) of chitosan was sprayed, followed by spraying $67.5 \mathrm{mg} \mathrm{l}^{-1}$ (final concentration) of local soils. To facilitate flocculation, when chitosan-modified soils were sprayed, the water was stirred.
Sampling

Samples were collected on Jul. 31 (before treatments applied), Aug. 10, Aug. 25, and Sep. 20 2007. For all the samples, equal volumes of surface, middle, and bottom

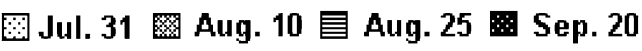
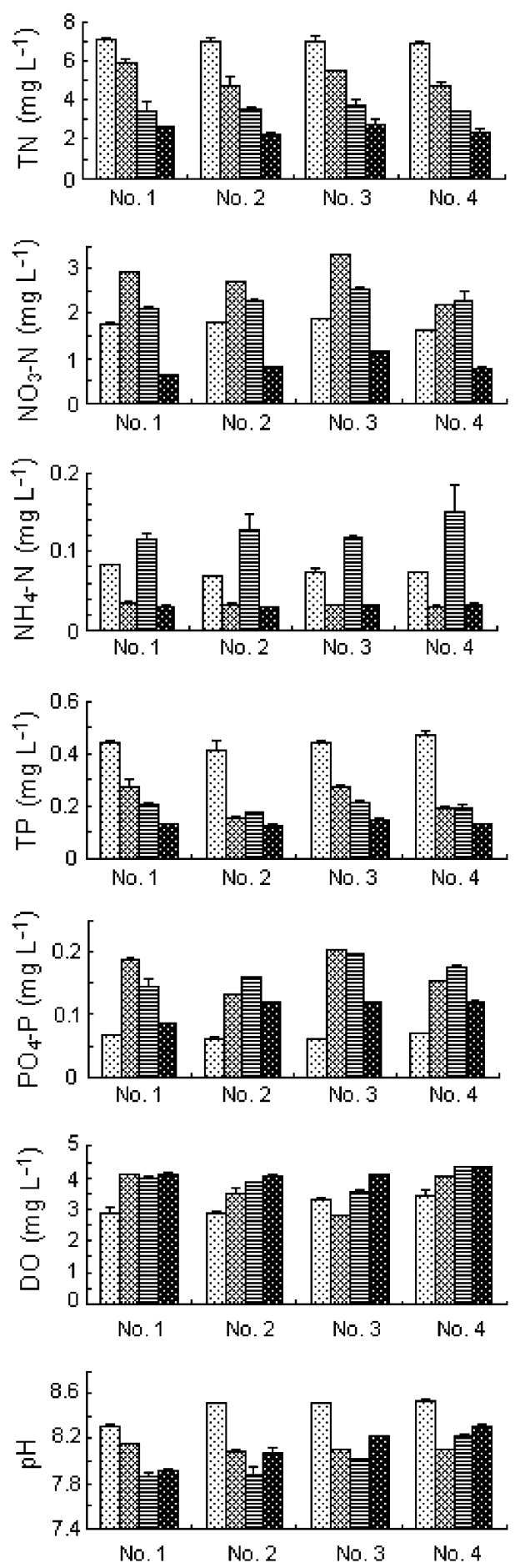

Figure 1 Comparison of chemical conditions in the four experimental boxes 
Table 1 Significant differences of chemical and biological parameters between sampling occasions and between boxes

\begin{tabular}{|c|c|c|}
\hline & Between sampling occasions & Between boxes \\
\hline $\mathrm{TN}\left(\mathrm{mg} \mathrm{l}^{-1}\right)$ & Jul. 31-Aug. 10-Aug. 25-Sep. 20 & NS \\
\hline $\mathrm{NO}_{3}-\mathrm{N}\left(\mathrm{mg} \mathrm{l}^{-1}\right)$ & Jul. 31-Aug. 10-Aug. 25-Sep. 20 & No. 3-no. 4 \\
\hline $\mathrm{NH}_{4}-\mathrm{N}\left(\mathrm{mg} \mathrm{l}^{-1}\right)$ & Jul. 31-Aug. 10 and Sep. 20-Aug. 25 & NS \\
\hline $\mathrm{TP}\left(\mathrm{mg}^{-1}\right)$ & Jul. 31-Aug. 10 and 25-Sep. 20 & NS \\
\hline $\mathrm{PO}_{4}-\mathrm{P}\left(\mathrm{mg} \mathrm{l}^{-1}\right)$ & Jul. 31-Aug. 10 and 25-Sep. 20 & NS \\
\hline $\mathrm{DO}\left(\mathrm{mg} \mathrm{l}^{-1}\right)$ & Jul. 31-Aug. 25-Sep. 20 & NS \\
\hline $\mathrm{pH}$ & Jul. 31-Aug. 10, 25 and Sep. 20 & No. $1-$ no. 4 \\
\hline Densities of protozoa (ind $1^{-1}$ ) & Jul. 31-Aug. 10, 25 and Sep. 20 & NS \\
\hline Densities of rotifer (ind $1^{-1}$ ) & NS & NS \\
\hline Densities of crustacean (ind ${ }^{-1}$ ) & Jul. 31 and Aug. 10-Aug. 25 and Sep. 20 & NS \\
\hline Numbers of identified taxa & Jul. 31-Aug. 10, 25 and Sep. 20 & No. 1 and $3-$ no. 2 \\
\hline Numbers of eukaryotic DGGE bands & Jul. 31-Aug. 10, 25 and Sep. 20 & NS \\
\hline Numbers of prokaryotic DGGE bands & NS & NS \\
\hline
\end{tabular}

$\alpha=0.05$ (univariate ANOVA) was used to assess statistical significance.

- significant differences between the compared objects, NS not significant

$(v / v / v=1: 1: 1)$ water were sampled and mixed. In qualitative analysis concerning the presence-absence of zooplankton, for each sample, 11 of water was filtered through glass-fiber GF/C filter (Whatmann, Maidstone, UK), and the filters were suspended in formalin solution. One liter of water was preserved with Lugol's solution, and after sedimentation for at least $24 \mathrm{~h}$, the solution was concentrated to $30 \mathrm{ml}$ for protozoa and rotifer counting. Six liters of water were filtered through no. 25 plankton net and preserved with formalin solution and finally concentrated to $30 \mathrm{ml}$ for crustacean counting. About $250 \mathrm{ml}$ of each sample was filtered through a glass-fiber $\mathrm{GF} / \mathrm{C}$ filter, and the filters were kept at $-20^{\circ} \mathrm{C}$ for DNA extraction (within $24 \mathrm{~h}$ ).

\section{Chemical Analysis and Morphological Identification}

Chemical parameters, including dissolved oxygen (DO), total nitrogen (TN), total phosphorus (TP), chlorophyll- $a$ (Chl-a), $\mathrm{NH}_{4}-\mathrm{N}, \mathrm{NO}_{3}-\mathrm{N}, \mathrm{PO}_{4}-\mathrm{P}$, and $\mathrm{pH}$ were determined according to standard methods [6]. Zooplankton were identified and counted under an Axioplan 2 imaging microscope (Zeiss, Jena, Germany) according to Wang [20], Chiang and Du [4], Research Group of Carcinology [13], Shen et al. [18], and Zhang and Huang [25].

\section{DNA Extraction and PCR Amplification}

DNA was extracted according to the method of Fuhrman et al. [5] and Yan et al. [21] with some modifications. Briefly, the frozen filters were thawed and then cut into small scraps. The scraps were briefly vortexed in $3 \mathrm{ml}$ lysis solution $(0.5 \%$ sodium dodecyl sulfate, $10 \mathrm{mM}$ Tris-Cl, $100 \mathrm{mM}$ EDTA, and $0.1 \mathrm{mg} \mathrm{ml}^{-1}$ proteinase $\mathrm{K}$ ) and followed by incubating in $55^{\circ} \mathrm{C}$ bath for $10 \mathrm{~h}$. After being centrifuged $\left(10 \mathrm{~min}, 10,000 \times \mathrm{g}, 20^{\circ} \mathrm{C}\right)$, the liquid was transferred into a new sterile tube and then applied with standard phenol-chloroform method.

As in our previous study [23], 16S ribosomal RNA (rRNA) and 18S rRNA genes were amplified with bacterial primers (F357-GC and R518) and eukaryotic primers (F1427-GC and R1616), respectively. Polymerase chain reaction (PCR) conditions for each $50-\mu$ reaction mixture were $1 \times$ PCR buffer, $2 \mathrm{mM} \mathrm{MgCl} 2,3.0 \mathrm{U}$ of Taq polymerase, $80 \mu \mathrm{M}$ of each deoxynucleotide (Fermentas Inc., Hanover, USA), $0.3 \mu \mathrm{M}$ of each primer, and approximately $40 \mathrm{ng}$ of template DNA. Touchdown PCR was performed on a GeneAmp PCR System 9600 thermal cycler (Perkin Elmer Cetus, USA) according to Yu et al. [23]. PCR products were visualized using $1.5 \%$ agarose gels stained with ethidium bromide. A negative control was prepared in the same manner as the samples except that DNA was excluded.

\section{Denaturing Gradient Gel Electrophoresis}

Denaturing gradient gel electrophoresis (DGGE) was performed with an INGENYphorU-2 system (INGENY International BV, Leiden, The Netherlands) using 9\% polyacrylamide (acrylamide/bisacrylamide $=37.5: 1$ ). PCR products containing approximately equal amounts of DNA of similar sizes were separated on a gel containing a linear gradient of denaturants (urea and formamide). The concentration of denaturants increased from $40 \%$ at the top to $60 \%$ at the bottom of the gels $(100 \%$ denaturant was defined as $7 \mathrm{M}$ urea and $40 \%$ formamide). Electrophoresis was performed at $60^{\circ} \mathrm{C}$ with $55 \mathrm{~mA}$ for $12 \mathrm{~h}$. After that, gels were stained in $1 \times$ TAE buffer containing $1 \times$ SYBR Gold (Molecular Probes Europe BV, Leiden, The Netherlands) 


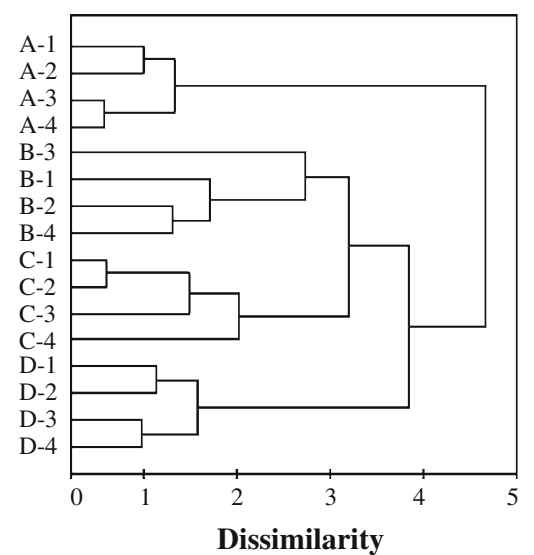

a

Figure 2 UPGMA clustering based on the measured chemical parameters (a) and zooplankton abundance (b). The abscissa shows Euclidean distance between samples. $A-D$ indicate the samples

for $20 \mathrm{~min}$ and then photographed using a UVP Imaging System (UVP Inc., CA, USA).

\section{Data Processing and Statistical Analysis}

Univariate analysis of variance (ANOVA) implemented by SPSS13.0 (SPSS Inc., Chicago, IL USS) was applied to compare sampling occasions (Jul. 31, Aug. 10 and 25, and Sep. 20 2007) and, separately, compare experimental conditions (nos. 1-4). The unweighted pair-group method using arithmetic averages (UPGMA) clustering was used to investigate the similarity among samples. Quantity One 4.6.2 (Bio-Rad Laboratories, CA, USA) was applied to analyze DGGE profile based on the position and intensity

a

ㄱ.: Jul. 31 图 Aug. 3 Aug. 7

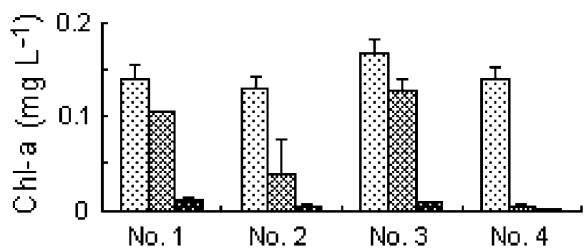

b

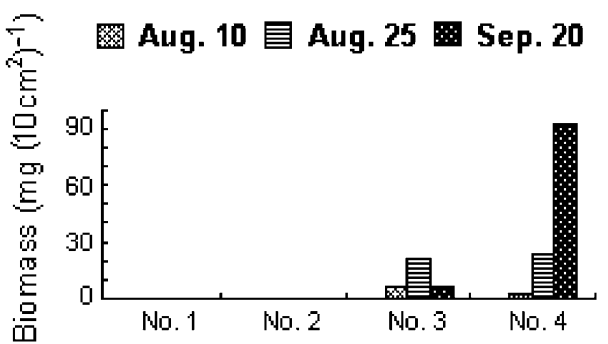

Figure 3 Comparison of concentration of Chl- $a$ in the short term (a) and the biomass of $V$. natans (b)

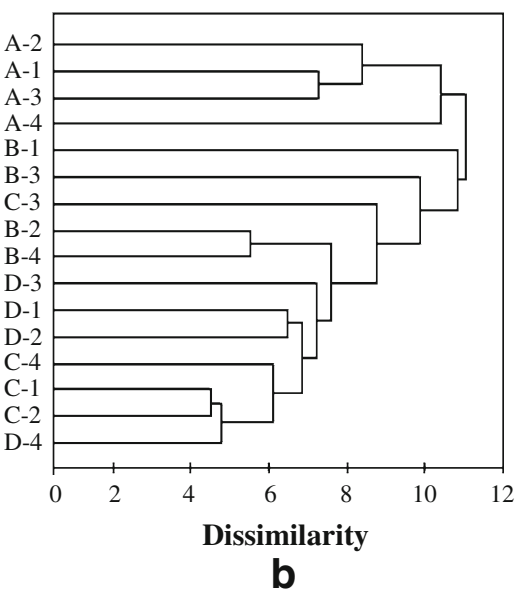

collected on Jul. 31, Aug.10, 25, and Sep. 20, respectively; 1-4 indicate the boxes. Except for $\mathrm{pH}$, chemical data were $\log (x+1)$ transformed, and zooplankton abundance was square-root-transformed

of matched bands. The Dice similarity coefficient was calculated using:

similarity $=200 \times \frac{\sum_{i=1}^{B} \operatorname{Min}\left(s_{i}, t_{i}\right)}{\sum_{i=1}^{B}\left(s_{i}+t_{i}\right)}$

where $s$ and $t$ are vectors representing the two lanes being compared. The components of $s\left(s_{1}, s_{2}, s_{3} \ldots s_{\mathrm{B}}\right)$ are the magnitudes of the band assigned to the $i$ th band type with $s_{i}=0$ if the lane does not have a band assigned to the $i$ th type [3]. The values for the bands of $t$ are similarly defined. The calculated similarity matrix was used to construct the UPGMA dendrograms.

To investigate the relationships between community composition and measured chemical variables, canonical correspondence analysis (CCA) was performed using CANOCO (version 4.15). Except for $\mathrm{pH}$, all chemical values were logs of measured values. Similarly, biological data were square-root-transformed before CCA to eliminate the influence of extreme values on ordination scores and to improve the normal distribution approximation. Forward selection and Monte Carlo permutations were used to select a minimum set of environmental using the significance level of 0.05 for including factors that are associated with the distribution of the planktonic organisms. The Mantel test was applied to evaluate the relationships between dissimilarity matrices of community composition and the selected factors using XLSTAT-Pro 2006 (Addinsoft, NY, USA). Finally, CCA ordination was run with the selected environmental factors, and statistical significance of the first two canonical axes was assessed. Variation partitioning CCA was performed to explore the percentage contributions of environmental factors and of experimental conditions. 
Figure 4 UPGMA clustering based on the position and intensity of the prokaryotic (a) and eukaryotic bands (b). The abscissa shows Dice coefficient between samples. $A-D$ indicated the samples collected on Jul. 31 , Aug.10, 25, and Sep. 20, respectively; $1-4$ indicated the boxes
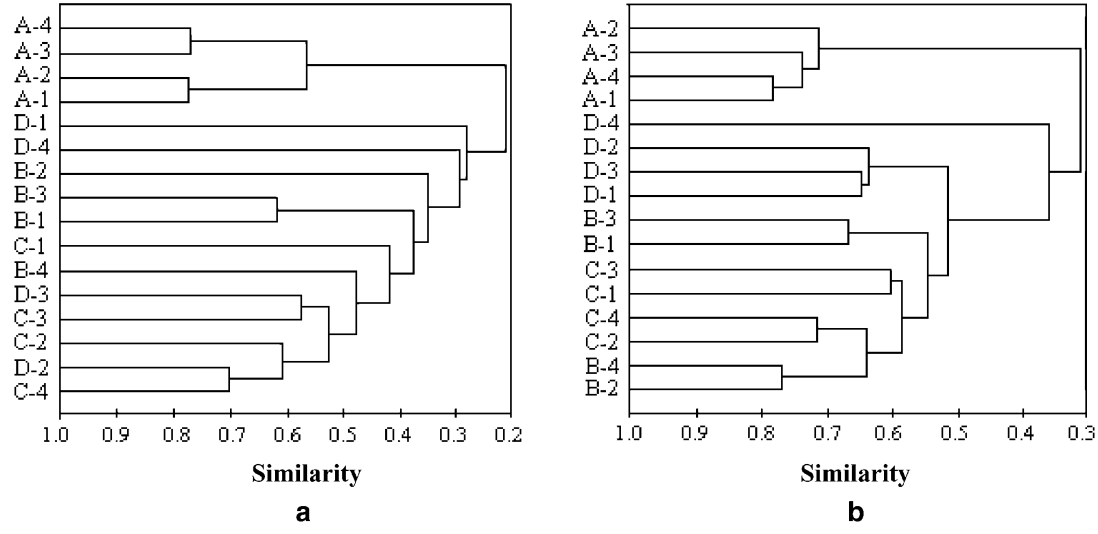

\section{Results}

Environmental Conditions

Figure 1 compares chemical conditions, clearly showing that concentrations of $\mathrm{TN}$ and $\mathrm{TP}$ in all the four experimental conditions (boxes) were significantly decreased from Jul. 31 to Aug. 10 (univariate ANOVA, $P<0.05$ ). Except for $\mathrm{pH}$ and the concentration of $\mathrm{NO}_{3}-\mathrm{N}$, there were no statistically significant differences among boxes. However, generally, there were significant differences between samples collected on Jul. 31 (before the original treatments were applied) and follow-up samples (Table 1). UPGMA clustering also indicated that the environmental conditions were generally different among the sampling occasions (Fig. 2a).

Samples collected in a shorter interval (Jul. 31-Aug. 3Aug. 7) showed that the concentrations of Chl- $a$ in boxes 2 and 4 were immediately decreased after cyanobacteria removal (univariate ANOVA, $P<0.05$ ), whereas boxes without the cyanobacteria removal process (1 and 3 ) maintained a high level 3 days later (Fig. 3a). Interestingly, $V$. natans in box 4 was successfully recovered, whereas that in box 3 (without cyanobacteria removal) showed only a modest growth initially and then decreased dramatically (Fig. 3b).

\section{Species Composition and Quantity of Plankton}

A total of 72 planktonic taxa were identified in the 16 samples; the number of identified taxa among boxes were not significantly different. Among all the identified taxa, protozoa and rotifers accounted for $45.8 \%$ and $34.7 \%$, respectively, whereas just $11.1 \%$ and $8.3 \%$ of the taxa belong to the alga and crustaceans, respectively. Only two taxa (one crustacean and one protozoan) were detected at all the 16 samples, whereas most of the taxa $(37.5 \%)$ were restricted to single samples. The densities of zooplanktonic groups (i.e., protozoa, rotifer, and crustacean) showed that there was no statistical difference between boxes (Table 1). UPGMA clustering based on the abundance of zooplanktonic organisms showed that the samples collected on Jul. 31 were different from the other samples (Fig. 2b).

\section{PCR-DGGE Fingerprinting of Plankton Community}

In the DGGE analysis of 16S rRNA genes, 59 different prokaryotic bands regarded as operational taxonomic units

Table 2 CCA results showing the percentage of explained variability by the first two axes

\begin{tabular}{|c|c|c|c|c|c|c|c|c|c|c|c|c|}
\hline \multirow{4}{*}{$\begin{array}{l}\text { Factors }^{\mathrm{a}} \\
\text { Axes }\end{array}$} & \multicolumn{4}{|c|}{ Prokaryotic bands } & \multicolumn{4}{|c|}{ Eukaryotic bands } & \multicolumn{4}{|c|}{ Zooplankton } \\
\hline & \multicolumn{2}{|l|}{$\mathrm{P}-\mathrm{A}$} & \multicolumn{2}{|c|}{ Band intensity } & \multicolumn{2}{|l|}{$\mathrm{P}-\mathrm{A}$} & \multicolumn{2}{|c|}{ Band intensity } & \multicolumn{2}{|l|}{$\mathrm{P}-\mathrm{A}$} & \multicolumn{2}{|l|}{ Abundance } \\
\hline & \multicolumn{2}{|c|}{$\mathrm{TP}, \mathrm{TN}, \mathrm{PO}_{4}$} & \multicolumn{2}{|c|}{$\mathrm{TP}, \mathrm{TN}, \mathrm{NO}_{3}$} & \multicolumn{2}{|c|}{$\mathrm{TP}, \mathrm{PO}_{4}, \mathrm{NO}_{3}, \mathrm{NH}_{4}$} & \multicolumn{2}{|c|}{$\mathrm{TP}, \mathrm{PO}_{4}, \mathrm{NO}_{3}$} & \multicolumn{2}{|l|}{$\mathrm{TP}, \mathrm{NO}_{3}$} & \multicolumn{2}{|c|}{$\mathrm{TN}, \mathrm{PO}_{4}, \mathrm{NH}_{4}$} \\
\hline & Percentage & $P$ & Percentage & $P$ & Percentage & $P$ & Percentage & $P$ & Percentage & $P$ & Percentage & $P$ \\
\hline Axis 1 & 24.3 & 0.005 & 22.1 & 0.005 & 28.0 & 0.005 & 26.9 & 0.005 & 22.3 & 0.005 & 27.9 & 0.005 \\
\hline Axis 2 & 9.1 & 0.025 & 9.7 & 0.02 & 12.0 & 0.01 & 13.1 & 0.01 & 11.4 & 0.005 & 9.6 & 0.04 \\
\hline
\end{tabular}

Analysis based on presence-absence data $(\mathrm{P}-\mathrm{A})$ were presented along with the band intensity or abundance. Values in the table were the percentage of explained variability with associated $P$ values.

${ }^{\text {a }}$ Chemical factors that had statistically significant and independent effects on the distribution of the planktonic organisms determined by Monte Carlo test (forward selection, $P<0.05$ ). $\mathrm{PO}_{4}$ indicates the concentration of $\mathrm{PO}_{4}-\mathrm{P} ; \mathrm{NO}_{3}$ indicates the $\mathrm{NO}_{3}-\mathrm{N} ; \mathrm{NH}_{4}$ indicates the $\mathrm{NH}_{4}-\mathrm{N}$ 
Table 3 Variation partitioning results of the CCA consider experimental boxes as blocks

\begin{tabular}{|c|c|c|c|c|c|c|c|c|c|c|c|c|}
\hline \multirow[b]{3}{*}{ Effects } & \multicolumn{4}{|c|}{ Prokaryotic bands } & \multicolumn{4}{|c|}{ Eukaryotic bands } & \multicolumn{4}{|l|}{ Zooplankton } \\
\hline & \multicolumn{2}{|l|}{$\mathrm{P}-\mathrm{A}$} & \multicolumn{2}{|c|}{ Band intensity } & \multicolumn{2}{|l|}{$\mathrm{P}-\mathrm{A}$} & \multicolumn{2}{|c|}{ Band intensity } & \multicolumn{2}{|l|}{$\mathrm{P}-\mathrm{A}$} & \multicolumn{2}{|l|}{ Abundance } \\
\hline & Percentage & $P$ & Percentage & $P$ & Percentage & $P$ & Percentage & $P$ & Percentage & $P$ & Percentage & $P$ \\
\hline$[\mathrm{E} \mid \mathrm{S}]$ & 39.4 & 0.005 & 38.0 & 0.005 & 53.9 & 0.005 & 48.0 & 0.005 & 33.7 & 0.005 & 45.6 & 0.005 \\
\hline$[\mathrm{S} \mid \mathrm{E}]$ & 5.8 & 0.29 & 6.8 & 0.17 & 6.6 & 0.07 & 5.9 & 0.15 & 5.1 & 0.485 & 4.8 & 0.41 \\
\hline$[\mathrm{E}+\mathrm{S}]$ & 0.8 & & 0.4 & & -1.1 & & -1.2 & & 0 & & -0.2 & \\
\hline Undetermined & 54.0 & & 54.8 & & 40.6 & & 47.3 & & 61.2 & & 49.8 & \\
\hline
\end{tabular}

Analysis based on presence-absence data $(\mathrm{P}-\mathrm{A})$ were presented along with the band intensity or abundance. Values in the table are the percentage of explained variability with associated $P$ values. $[\mathrm{E} \mid \mathrm{S}]$ is the sole effect of environmental factors, $[\mathrm{S} \mid \mathrm{E}]$ is the sole effect of boxes, and $[\mathrm{E}+\mathrm{S}]$ is the overlap between environmental predictors and boxes

were detected. The number of bands detected per sample ranged from 10 to 30 , with an average of 20.4. Of these prokaryotic bands, nine were site-specific, and none of the 59 bands were common to all of the samples. Additionally, the numbers of detected $16 \mathrm{~S}$ ribosomal DNA (rDNA) bands were not statistically different between sampling occasions or among boxes. UPGMA clustering based on the position and intensity of the prokaryotic bands indicated that the samples derived on Jul. 31 were different from the other samples (Fig. 4a).

In the DGGE analysis of $18 \mathrm{~S}$ rRNA genes, 45 different eukaryotic bands were identified. The number of bands detected per sample ranged from 9 to 18. Of these eukaryotic bands, three were restricted to single samples, and only one band was detected in all 16 samples. The numbers of eukaryotic DGGE bands in the samples collected on Jul. 31 were significantly smaller than for other samples. Also, UPGMA clustering based on the position and intensity of the eukaryotic bands also indicated that the samples derived on Jul. 31 were different from the other samples (Fig. 4b).
Plankton Community Succession in Relation to Chemical Factors

Different chemical factors had statistically significant and independent effects on the distribution of different planktonic groups (prokaryotic and eukaryotic bands; zooplankton organisms). In brief, the concentration of TP was generally found to be significantly related to the distribution of the planktonic organisms, whereas the $\mathrm{pH}$ and DO were not significantly related to any group (Table 2). Also, the Mantel test also showed that the dissimilarity matrices based on the selected factors and the targeted group were significantly related $(r=0.331-0.593$, $P<0.01)$. For all the groups, the first two CCA axes explained more than $30 \%$ of total variability, and both of the canonical axes were statistically significant (Monte Carlo test, $P<0.05$, Table 2).

Analyses based on presence-absence data $(\mathrm{P}-\mathrm{A})$, band intensity, and zooplankton abundance indicated that only the chemical predictors were significant in explaining community composition (i.e., the $[\mathrm{E} \mid \mathrm{S}]$ fraction, 33.7-

Table 4 Results of CCA to determine the relative contribution (percentage of total variation) and associated $P$ values for each environmental variable, which had statistically significant and independent effects on the distribution of the related plankton group

\begin{tabular}{|c|c|c|c|c|c|c|c|c|c|c|c|c|}
\hline \multirow[b]{3}{*}{ Variables } & \multicolumn{4}{|c|}{ Prokaryotic bands } & \multicolumn{4}{|c|}{ Eukaryotic bands } & \multicolumn{4}{|c|}{ Zooplankton } \\
\hline & \multicolumn{2}{|l|}{$\mathrm{P}-\mathrm{A}$} & \multicolumn{2}{|c|}{ Band intensity } & \multicolumn{2}{|l|}{$\mathrm{P}-\mathrm{A}$} & \multicolumn{2}{|c|}{ Band intensity } & \multicolumn{2}{|l|}{$\mathrm{P}-\mathrm{A}$} & \multicolumn{2}{|l|}{ Abundance } \\
\hline & Percentage & $P$ & Percentage & $P$ & Percentage & $P$ & Percentage & $P$ & Percentage & $P$ & Percentage & $P$ \\
\hline TP & 20.2 & 0.005 & 18.4 & 0.005 & 25.9 & 0.005 & 25.3 & 0.005 & 21.9 & 0.005 & - & \\
\hline $\mathrm{PO}_{4}-\mathrm{P}$ & 19.3 & 0.005 & - & & 18.1 & 0.005 & 16.8 & 0.005 & - & & 26.7 & 0.005 \\
\hline $\mathrm{TN}$ & 17.7 & 0.01 & 17.7 & 0.005 & - & & - & & - & & 21.0 & 0.005 \\
\hline $\mathrm{NO}_{3}-\mathrm{N}$ & - & & 6.76 & NS & 11.1 & NS & 13.1 & NS & 11.4 & 0.045 & - & \\
\hline $\mathrm{NH}_{4}-\mathrm{N}$ & - & & - & & 6.42 & NS & - & & - & & 10.8 & 0.005 \\
\hline
\end{tabular}

$\alpha=0.05$ was used to assess statistical significance

- indicated that the factor was not selected by Monte Carlo test (forward selection, $P<0.05$ ) for the targeted group, $N S$ not significant 
Figure 5 Photographs showing the water conditions before and after cyanobacteria removal
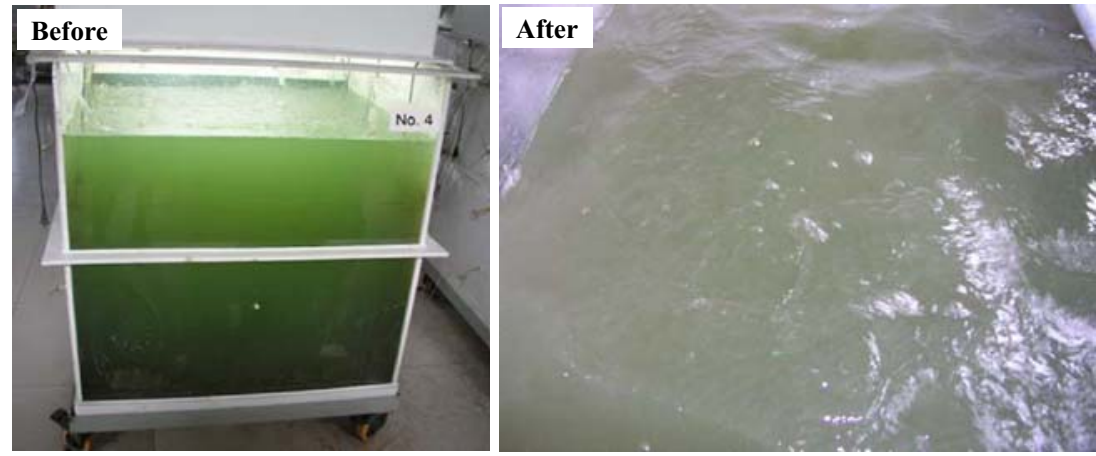

$53.9 \%$ of total variation, $P<0.05)$. There were no significant unique box effects (i.e., the $[\mathrm{S} \mid \mathrm{E}]$ fraction, $P>0.05$ ) for all the groups (Table 3). Since the selected chemical factors explained a substantial fraction of total variation, we further evaluated which of these were most important for the targeted group (Table 4). For all groups except zooplankton abundance, TP was the factor that explained the greatest proportion of community variation.

\section{Discussion}

Eutrophication is a worldwide environmental problem that has tremendous impacts on the sustainable development of society and economy $[8,22]$. Cyanobacterial bloom is one of the most common responses to eutrophication, and it is occurring with increased frequency. There have been many efforts to control eutrophication; however, often, the results have been unsatisfactory. In 2006, Pan and colleagues [10, $11,26]$ developed a quick and inexpensive method to remove harmful cyanobacterial blooms using chitosanmodified local soils. The mechanism of netting and bridging was reported as the dominant factor in improving removal efficiency [26]. The protonation of amino groups of chitosan in solution makes them positively charged and thereby attracting negatively charged algal cells. In addition, chitosan also flocculates particles by netting and bridging as other polymers. Consequently, algal removal efficiency of chitosan-modified soils was improved considerably by enhancing the netting and bridging function. Although this new technique can effectively remove the harmful cyanobacterial blooms, it was necessary to evaluate the potential ecological effects before it is widely applied. For example, although local mussels [C. plicata (Leach)] and aquatic macrophytes (M. spicatum) were not affected by the cyanobacteria removal process [26], further studies are still necessary to evaluate some more sensitive groups that may result in potential bottom-up or top-down effects in the ecosystem.

As highlighted in previous studies [2, 21], planktonic organisms are ideal for monitoring the conditions of aquatic environments. Recently, PCR-DGGE fingerprinting has also been applied to study the diversity and dynamics of natural plankton community $[15,23]$. In contrast to the morphological method, multiple samples can be analyzed simultaneously with canonical and uniform fingerprinting procedures, making it practical to perform comparative analyses. In the present study, we used PCR-DGGE fingerprinting together with taxonomical identification to study plankton community succession during the ecological simulation experiment.

In the experiments, the harmful cyanobacterial blooms were effectively removed, which was apparent by viewing the water before and after cyanobacteria removal (Fig. 5). Removal was also evidenced by Chl- $a$ concentration. It immediately decreased to a low level in boxes 2 and 4 after cyanobacteria removal treatment; however, 3 days later, it only slightly decreased in boxes 1 and 3 (Fig. 3a). The rapid decrease in the control boxes may attributed to natural death. According to Pan et al. artificial system simulating bloom phenomenon can be maintained about 1 week because there may be no algal cells reproducing as there would be in natural lakes where blooming can last several

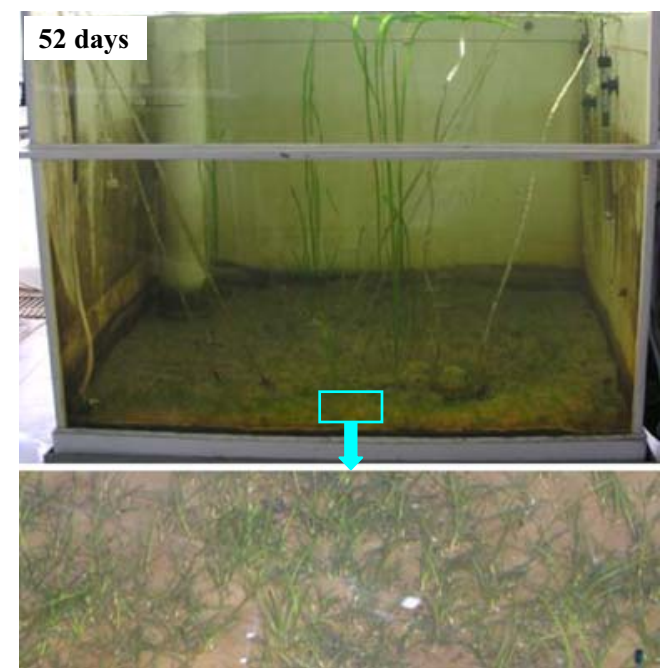

Figure 6 Photographs showing the conditions of the $V$. natans in box 4, 52 days after cyanobacteria removal 
months (e.g., in Taihu Lake). The quantity of zooplankton determined by a morphological method showed that many of the identified species had a comparatively high abundance (data not shown). Nevertheless, there were no significant differences between the removal/no removal treatments.

In order to control the eutrophication by ecological restoration, which aims to reverse the shift from a phytoplankton-dominant to a macrophyte-dominant state, more research is needed on improving environmental conditions instead of merely planting macrophytes [12]. Interestingly, the environmental conditions can be improved as by product of cyanobacterial cells removal using chitosan-modified sediment [24]. To assess this, V. natans was planted in box 4 to recover the macrophytes after cyanobacterial blooms were removed. As expected, vegetation was successfully recovered (Fig. 6), which is clearly supported by the continuous increase of $V$. natans in box 4 (Fig. 3b). However, the planted $V$. natans in the control box (box 3) showed only a modest increase at first and then decreased substantially (Fig. 3b). These observations suggest that when the modified soils flocculate algal cells and increase transparency, they also can improve the sediments' ability to support growth of submerged vegetation. Additionally, the concentration of TP was found to be one of the most important environmental predictors of plankton community structure, as has been observed previously in natural ecosystems $[7,23]$. The concentration of $\mathrm{PO}_{4}-\mathrm{P}$ also played an important role. Generally, phosphorus is the critical limiting factor in the freshwater ecosystem [17], whereas nitrogen tends to be the critical factor in the marine environment [14].

The similarity of prokaryotic and eukaryotic plankton communities, as showed by the DGGE bands of $16 \mathrm{~S}$ rDNA and $18 \mathrm{~S}$ rDNA, respectively, indicates that the samples derived on Jul. 31 were different from the other samples (Fig. 4). These suggest that the four boxes were at the same environmental conditions at the beginning of experiment, as also supported by the chemical analysis and morphological analysis (Fig. 2). If the cyanobacteria removal process significantly affects the targeted plankton community, the conditions in boxes dealing with cyanobacteria removal (boxes 2 and 4) as compared to those without cyanobacteria removal process (boxes 1 and 3) are expected to be clearly different. But the DGGE analysis showed no clear subgroups (Fig. 4), indicating that there were not significantly different. Chemical analysis also indicated no significant differences between treatments, and the samples clustered into subgroups only according to sampling date (Fig. 2a). One possible explanation of this similarity in plankton succession between the removal/no removal treatments is that local soils were applied, and the aquatic environment may be similar to natural sediments resus- pended by winds or other agitation. Additionally, the chitosan used to modify the local soils is a natural, nontoxic, and biodegradable polymer and is not a pollutant. Therefore, although the netting and bridging function of modified soils flocculated the negatively charged algal cells, there may be no harmful effects to other planktonic organisms.

In summary, the present study suggests that cyanobacterial blooms in the artificial systems can be rapidly and effectively removed using chitosan-modified soils. More importantly, the $V$. natans can successfully recovered after the cyanobacteria removal process (in box 4). In contrast, the plankton community succession was not significantly affected by the treatment, suggesting that there may be no harmful effects to the ecosystem. Findings indicate that cyanobacterial bloom removal using chitosan-modified soils can play an important role in controlling cyanobacterial blooms result from eutrophication. It should also be noted that further field studies are needed to study planktonic organisms' responses in natural environment subjected to the treatment.

Acknowledgments The authors gratefully acknowledge Prof. Thomas A. Louis (Johns Hopkins Bloomberg School of Public Health, USA) for help with the English. This work was funded by the Major State Basic Research Development Program of China (2008CB418105), the Foundation of the State Key Laboratory of Freshwater Ecology and Biotechnology (2008FB016), and the National Natural Science Foundation of China (30770298 and 30570240).

\section{References}

1. Beisner BE (2001) Plankton community structure in fluctuating environments and the role of productivity. Oikos 95:496-510

2. Bianchi F, Acri F, Aubry FB, Berton A, Boldrin A, Camatti E, Cassin D, Comaschi A (2003) Can plankton communities be considered as bio-indicators of water quality in the Lagoon of Venice? Mar Pollut Bull 46:964-971

3. Bio-Rad Laboratories (2005) Quantity One ${ }^{\circledR}$ user guide for version 4.6.2 Windows and Macintosh, pp 12-10

4. Chiang SC, Du NS (1979) Fauna sinica, crustacean: freshwater Cladocera. Science Press, Academia Sinica, Beijing (in Chinese)

5. Fuhrman JA, Comeau DE, Hagström Å, Chan AM (1988) Extraction from natural planktonic microorganisms of DNA suitable for molecular biological studies. Appl Environ Microbiol 54:1426-1429

6. Huang XF (2000) Survey, observation and analysis of lake ecology. China Standard Press, Beijing (in Chinese)

7. Jeppesen E, Jensen JP, Søndergaard M, Lauridsen T, Landkildehus F (2000) Trophic structure, species richness and biodiversity in Danish lakes: changes along a phosphorus gradient. Freshwater Biol 45:201-218

8. Jin $\mathrm{XC}, \mathrm{Xu}$ QJ, Huang CZ (2005) Current status and future tendency of lake eutrophication in China. Sci China Ser C 48:948-954

9. Meijer ML (2000) Biomanipulation in The Netherlands-15 years of experience. $\mathrm{PhD}$ thesis, Wageningen University 
10. Pan G, Zhang MM, Chen H, Zou H, Yan H (2006) Removal of cyanobacterial blooms in Taihu Lake using local soils. I. Equilibrium and kinetic screening on the flocculation of Microcystis aeruginosa using commercially available clays and minerals. Environ Pollut 141:195-200

11. Pan G, Zou H, Chen H, Yuan XZ (2006) Removal of harmful cyanobacterial blooms in Taihu Lake using local soils. III. Factors affecting the removal efficiency and an in situ field experiment using chitosan-modified local soils. Environ Pollut 141:206-212

12. Qin BQ, Yang LY, Chen FZ, Zhu GW, Zhang L, Chen YY (2006) Mechanism and control of lake eutrophication. Chin Sci Bull 51:2401-2412

13. Research Group of Carcinology, Institute of Zoology, Academia Sinica (1979) Fauna sinica, crustacean: freshwater Copepoda. Science Press, Academia Sinica, Beijing (in Chinese)

14. Ryther JH, Dunstan WM (1971) Nitrogen, phosphorus, and eutrophication in the coastal marine environment. Science 171:1008-1013

15. Savin MC, Martin JL, LeGresley M, Giewat M, Rooney-Varga J (2004) Plankton diversity in the Bay of Fundy as measured by morphological and molecular methods. Microb Ecol 48:51-65

16. Scheffer M, Carpenter S, Foley JA, Folke C, Walker B (2001) Catastrophic shifts in ecosystems. Nature 413:591-596

17. Schindler DW (1974) Eutrophication and recovery in experimental lakes: implications for lake management. Science 184:897-899

18. Shen YF, Zhang ZS, Gong XJ, Gu MR, Shi ZX, Wei YX (1990) Modern biomonitoring techniques using freshwater microbiota. China Architecture and Building Press, Beijing (in Chinese)
19. Ternjej I, Tomec M (2005) Plankton community and related environmental factors in the oligotrophic Lake Vrana. Period Biol 107:321-328

20. Wang JJ (1961) Freshwater rotifers in China. Science Press, Beijing (in Chinese)

21. Yan QY, Yu YH, Feng WS, Deng WN, Song XH (2007) Genetic diversity of plankton community as depicted by PCRDGGE fingerprinting and its relation to morphological composition and environmental factors in Lake Donghu. Microb Ecol 54:290-297

22. Yang XE, Wu X, Hao HL, He ZL (2008) Mechanisms and assessment of water eutrophication. J Zhejiang Univ Sci B 9: 197-209

23. Yu YH, Yan QY, Feng WS (2008) Spatiotemporal heterogeneity of plankton communities in Lake Donghu, China, as revealed by PCR-denaturing gradient gel electrophoresis and its relation to biotic and abiotic factors. FEMS Microbiol Ecol 63:328-337

24. Zhang ML, Pan G, Chen H, Tian BH, Gao S, Yuan XZ (2007) Study of the effect on water quality improvement by removal of algal blooms using modified sediment. Acta Scientiae Circumstantiae 27:13-17 (in Chinese)

25. Zhang ZS, Huang XF (1991) Research methods of freshwater plankton. Science Press, Beijing (in Chinese)

26. Zou H, Pan G, Chen H, Yuan XZ (2006) Removal of cyanobacterial blooms in Taihu Lake using local soils. II. Effective removal of Microcystis aeruginosa using local soils and sediments modified by chitosan. Environ Pollut 141:201-205 